\title{
Severe hypertriglyceridemia and colchicine intoxication following suicide attempt
}

\author{
This article was published in the following Dove Press journal: \\ Drug Design, Development and Therapy \\ Number of times this article has been viewed
}

\author{
Shaul Lev' \\ David Snyder ${ }^{2}$ \\ Carmil Azran ${ }^{3}$ \\ Victor Zolotarsky' \\ Arik Dahan ${ }^{4}$ \\ 'Intensive Care Unit, Rabin Medical \\ Center, Petah-Tikva, ${ }^{2}$ Sackler School \\ of Medicine NY/American Program, \\ Tel-Aviv University, Tel Aviv, ${ }^{3}$ Clinical \\ Pharmacy, Herzliya Medical Center, \\ Herzliya, ${ }^{4}$ Department of Clinical \\ Pharmacology, School of Pharmacy, \\ Faculty of Health Sciences, Ben- \\ Gurion University of the Negev, \\ Beer-Sheva, Israel
}

\begin{abstract}
Colchicine overdose is uncommon but potentially life threatening. Due to its serious adverse systemic effects, overdose must be recognized and treated. We report a case of an 18 -year-old female who ingested $18 \mathrm{mg}(\sim 0.4 \mathrm{mg} / \mathrm{kg})$ of colchicine in a suicide attempt. The patient's clinical manifestations included abdominal cramps, vomiting, pancytopenia, hypocholesterolemia, and rhabdomyolysis. Two unique manifestations of toxicity in this patient were profound and persistent, severe hypertriglyceridemia and electrolyte imbalance, mainly hypophosphatemia, with no other evident cause except the colchicine intoxication. Following intensive supportive treatment, including ventilator support, $\mathrm{N}$-acetylcysteine, granulocyte colony stimulating factor, electrolyte repletion, and zinc supplementation, the patient made a complete recovery. Colchicine intoxication is a severe, life-threatening situation that should be followed closely in intensive care units. Severe changes in body functions can rapidly develop, as previously described in the literature. To our knowledge, this extremely elevated triglyceride level has never been reported without the administration of propofol, and requires further evaluation.
\end{abstract}

Keywords: colchicine, intoxication, hypophosphatemia, hypertriglyceridemia

\section{Introduction}

A previously healthy 18-year-old female was admitted to our intensive care unit (ICU) after being transferred from a different hospital due to ingestion of approximately 30 tablets of colchicine $(18 \mathrm{mg}) 3$ days prior.

Colchicine is a neutral and lipophilic alkaloid from the plant Colchicum autumnale and is a microtubule polymerization inhibitor. It is primarily used to treat acute gout as well as familial Mediterranean fever. It has been used in the treatment of gouty arthritis for centuries. Adverse effects of colchicine use are characterized by "crampy" abdominal pain, diarrhea, nausea, vomiting, headaches, and fatigue. Colchicine toxicity has been characterized by cytopenias (especially thrombocytopenia), electrolyte imbalance (especially hypophosphatemia and hypozincemia), and elevated creatinine phosphokinase (CPK).

At the time of admission (3rd day post-ingestion), she was alert and oriented but had suffered from vomiting and diarrhea for more than 2 days. She experienced midepigastric pain with intermittent bilious vomiting. The patient also presented with hepatic disturbances and metabolic acidosis. The results of a complete evaluation for infectious disease were negative.

Her vital signs were unremarkable except for a pulse of 143 beats/minute and shortness of breath. There was mild abdominal distension but bowel sounds were normal. Written informed consent for the case details to be published was provided by the patient.
Correspondence: Arik Dahan Department of Clinical Pharmacology, School of Pharmacy, Faculty of Health Sciences, Ben-Gurion University of the Negev, PO Box 653, Beer-Sheva 84I05, Israel

Tel +97286479483

Fax +97286479303

Email arikd@bgu.ac.il 


\section{Diagnostic assessment}

Electrocardiogram was unremarkable. She presented with elevated partial thromboplastin time, international normalized ratio of $52 \mathrm{sec}$ and 2.4 respectively. Her platelet count was $100,000 / \mu \mathrm{L}$ and her fibrinogen was $205 \mathrm{mg} / \mathrm{dL}$.

Plasma electrolytes on admission (3rd day post-ingestion) were significant for mildly decreased phosphorous of $2.1 \mathrm{mg} / \mathrm{dL}$, potassium $3.18 \mathrm{mEq} / \mathrm{L}$, magnesium $1.39 \mathrm{mg} / \mathrm{dL}$, and corrected calcium of $7.16 \mathrm{mg} / \mathrm{dL}$. Despite receiving extensive electrolyte supplementation since the day of admission, persistent, severe electrolyte imbalances persisted and were difficult to control. Her electrolyte measurements included magnesium ranging from $1.39 \mathrm{mg} / \mathrm{dL}$ to $1.76 \mathrm{mg} / \mathrm{dL}$ and potassium ranging from $2.7 \mathrm{mg} / \mathrm{dL}$ to $3.49 \mathrm{mg} / \mathrm{dL}$. The most profound electrolyte disturbance was hypophosphatemia reaching as low as $0.7 \mathrm{mg} / \mathrm{dL}$ on day 8 . Rhabdomyolysis was diagnosed by elevated CPK levels up to 8,500 units/L and the urine tested positive for myoglobin (Figure 1).

On admission (3rd day post-ingestion) she also had an elevated triglyceride level of $816 \mathrm{mg} / \mathrm{dL}$ which later reached a peak of $1,273 \mathrm{mg} / \mathrm{dL}$ on day 10 . This was accompanied by HDL levels ranging from $7 \mathrm{mg} / \mathrm{dL}$ to $13.7 \mathrm{mg} / \mathrm{dL}$ on day 4 and day 10 , respectively.

\section{Therapeutic intervention}

On arrival, she was given n-acetylcysteine (NAC) based on a previous case report describing successful NAC treatment in colchicine intoxication. ${ }^{1}$ Her paracetamol level was undetectable. No change in her condition was noted post-treatment.

The patient developed pancytopenia on her 4th day postingestion which resolved on day 9 under granulocyte colony stimulating factor treatment. ${ }^{2-5}$ Absolute neutrophil count was $8,100 / \mu \mathrm{L}$ and reached nadir $300 / \mu \mathrm{L}$ on day 6 . Hemoglobin nadir $7.8 \mathrm{~g} / \mathrm{dL}$ was on day 8 . Platelets nadir was on day 7 with a level of $20,000 / \mu \mathrm{L}$. Mean platelet volume of the patient was $6.8 \mathrm{fL}$ on admission indicating bone marrow failure. On day 5 the patient exhibited mucosal damage and bleeding mainly in the mouth and eyes. On day 5 she received the granulocyte colony stimulating factor (filgrastim) treatment. Since highgrade fever had developed on day 4 , she was treated with piperacillin/tazobactam. Platelet transfusions were given on day 7 when the absolute number decreased below $20,000 / \mu \mathrm{L}$. On day 8 there was an improvement in her counts.

On day 6 post-ingestion she developed respiratory distress and hypoxemia accompanied by bilateral pulmonary infiltrates, compatible with the diagnosis of acute lung injury (ALI), which was treated with non-invasive mechanical ventilation and negative fluid balance. The ALI resolved on day 9.

The patient was also treated with intravenous multivitamins and trace elements with oral zinc supplementation to avoid hypozincemia.

\section{Follow-up and outcomes}

Fourteen days post-ingestion the patient was transferred back to the referring hospital in a good condition. Figure 2 shows the changes, over time, of CPK and phosphorus and their return to acceptable levels.

\section{Discussion}

Colchicine is a neutral and lipophilic alkaloid. An overdose of colchicine inhibits cell division by fixing the intracellular tubule and arresting polymerization into microtubules; thus,

\section{Timeline}

\begin{tabular}{|c|c|c|c|c|c|c|c|c|c|}
\hline Elevated CPK & & & & & & & & & \\
\hline \multirow{2}{*}{\multicolumn{10}{|c|}{ Neutropenia }} \\
\hline & & & & & & & & & \\
\hline & & & & & & & & & \\
\hline \multicolumn{10}{|l|}{ Thrombocytopenia } \\
\hline & & & & & & & & & \\
\hline \multicolumn{10}{|l|}{ Fever } \\
\hline & & & & & & & & & \\
\hline \multicolumn{10}{|l|}{ Hypophosphatemia } \\
\hline & & & & & & & & & \\
\hline \multicolumn{10}{|l|}{ Coagulopathy } \\
\hline & & & & & & & & & \\
\hline \multicolumn{10}{|l|}{ Respiratory distress } \\
\hline & Day 3 & Day 4 & Day 5 & Day 6 & Day 7 & Day 8 & Day 9 & Day 10 & Day 11 \\
\hline
\end{tabular}

Figure I Time-course of patient's laboratory findings and symptoms.

Notes: Elevated CPK (>I80 units/L); neutropenia (neutrophil count $<1,000 \mu \mathrm{L}$ ); thrombocytopenia (platelets $<100,000 / \mu \mathrm{L})$; fever $\left(\right.$ temp $>38 . \mathrm{I}^{\circ} \mathrm{C}$ ); hypophosphatemia (phosphorus $<2.5 \mathrm{mg} / \mathrm{dL}$ ); coagulopathy (INR $>1.7$ ); respiratory distress (RR $>20 / \mathrm{min}, \mathrm{PaO} 2 / \mathrm{FiO} 2<200$ ).

Abbreviations: CPK, creatinine phosphokinase; INR, international normalized ratio; RR, respiratory rate. 


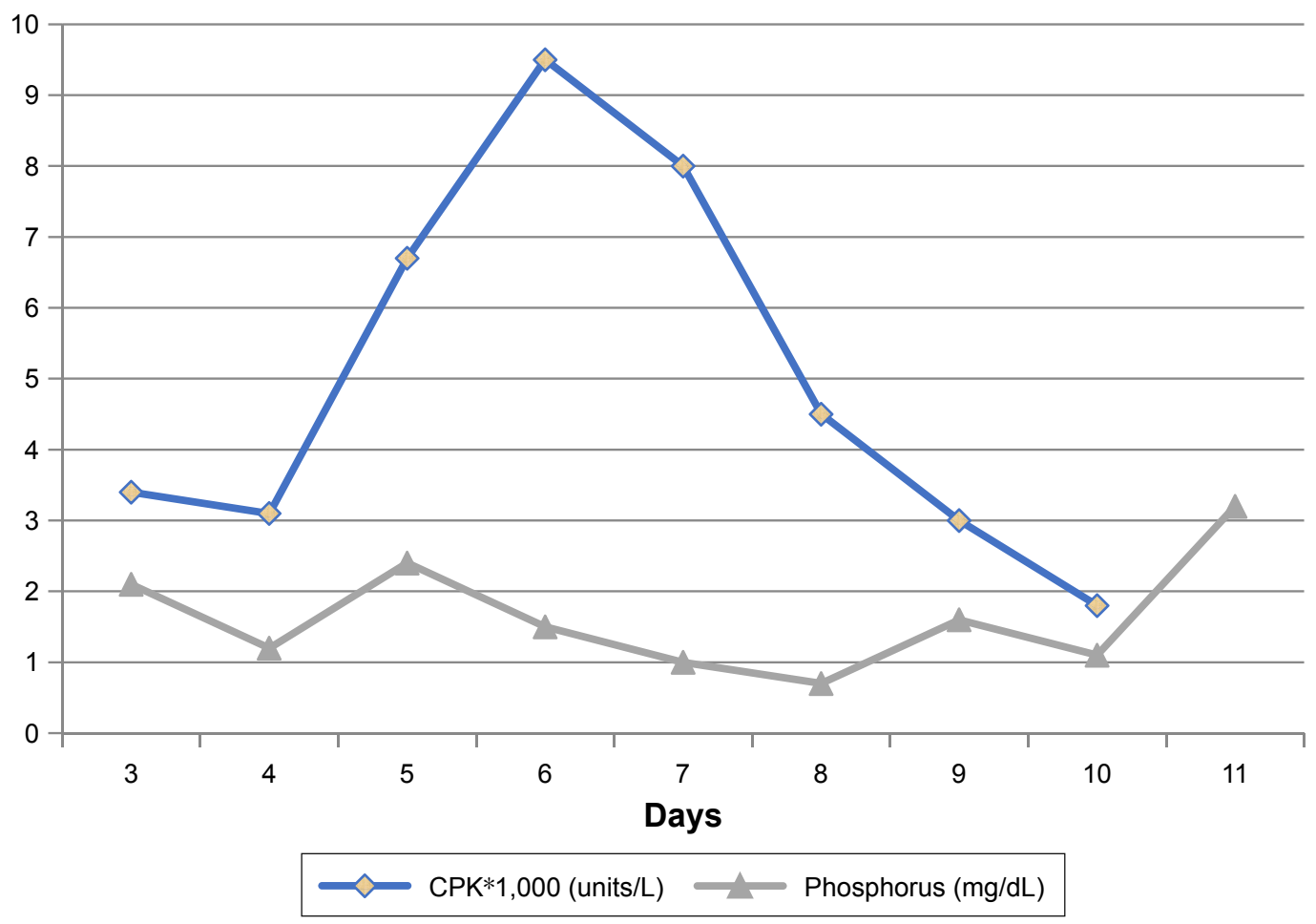

Figure 2 Phosphorus levels and CPK levels over time. Abbreviation: CPK, creatinine phosphokinase.

mitosis and transport systems within the cells are disrupted. Tissues that are most susceptible to anti-mitotic effects are tissues with high division index, like mucosal surfaces, skin, and bone marrow. ${ }^{3}$ Additionally, oxidative stress-induced cellular damage by colchicine was evident in the improvement seen upon treatment with NAC. Our patient displayed many signs of endothelial and mucosal damage including conjunctival bleeding, diarrhea, disseminated intravascular coagulation (DIC), and ALI. First symptoms of acute toxicity occur within the first 24 hours of ingestion and include nausea, vomiting, diarrhea, anorexia, and abdominal pain. Multi-organ failure usually develops 24 to 72 hours after ingestion. Bone marrow suppression, hemolytic anemia, liver damage, renal failure, respiratory distress syndrome, arrhythmias, rhabdomyolysis, neuromuscular disturbances, and DIC can also develop. Delayed presentation is associated with a poor prognosis. ${ }^{9}$

Elevated triglyceride levels have been previously reported by others, ${ }^{6}$ but were attributed to propofol infusion syndrome. However, in our patient, propofol was not administered. We hypothesize that the high level of triglycerides was partly due to intense inflammatory response and a decrease in lipase activity. The low HDL levels and high CRP levels support the inflammatory concept. However, the triglycerides level continued to rise despite resolution of other symptoms and increase in HDL level, implying that inflammation by itself is not enough to explain such severe hypertriglyceridemia. Moreover, after oral ingestion, the mean half-life of colchicine is 9 to 16 hours. It is rapidly absorbed from the gastrointestinal tract after ingestion and undergoes significant first-pass hepatic metabolism. Since the triglyceride levels continued to elevate 10 days after oral ingestion, it is highly unlikely that the effect was pharmacological. To our knowledge no direct or indirect effects of colchicine in terms of apolipoprotein metabolism have been described.

The patient required massive doses of phosphate supplementations due to an unknown mechanism, but it was probably related to cellular redistribution, like that seen in re-feeding syndrome. The intensity of the phosphate drop was overwhelming and exceeded our protocol of $18 \mathrm{mmol}$ to $21 \mathrm{mmol}$ of potassium phosphate. The rhabdomyolysis that was present preceded the nadir in phosphate level and was most likely not the cause of it.

The patient was also treated with zinc supplementation due to hypozincemia which is very common in critically ill patients. ${ }^{7}$ In addition, the rationale of avoiding hypozincemia was based on an animal study indicating severe mucosal injury when colchicine is given in animals with zinc deficiency. ${ }^{8}$ This could be related to the crucial role of zinc in the function of the microtubule. 


\section{Conclusion}

Colchicine intoxication is a severe, life-threatening situation that should be followed closely in ICUs. Severe changes in body functions can develop rapidly. This patient displayed some unique characteristics with severe bone marrow suppression and profound hypophosphatemia requiring intensive electrolyte repletion. To our knowledge, the extremely high triglyceride level has never been reported without the administration of propofol, and requires further evaluation.

\section{Disclosure}

The authors report no conflicts of interest in this work.

\section{References}

1. Ioulia I, Lan J, Chin C, Werb R, Levin A. Massive colchicine overdose with recovery. Case Rep Nephrol Urol. 2012;2(1):20-24.

2. Harris R, Marx G, Gillet M, Kark A, Arunanthy S. Colchicine-induced bone marrow suppression: treatment with granulocyte colony-stimulating factor. J Emerg Med. 2000;18(4):435-440.
3. Harris R, Gillet M. Colchicine poisoning-overview and new directions. Emerg Med. 1988;10:161-167.

4. Critchley JA, Critchley LA, Yeung EA, Young RP, Young RJ, Chan TY, Goh VK. Granulocyte colony-stimulating factor in the treatment of colchicine poisoning. Hum Exp Toxicol. 1997;16(4):229-232.

5. Grossmann A, Lenox J, Deisher TA, Ren HP, Humes JM, Kaushansky K, Sprugel KH. Synergistic effects of thrombopoietin and granulocytestimulating factor on neutrophil recovery in myelosuppressed mice. Blood. 1996;88(9):3363-3370.

6. Montiel V, Huberlant V, Vincent MF, Bonbled F, Hantson P. Multiple organ failure after an overdose of less than $0.4 \mathrm{mg} / \mathrm{kg}$ of colchicine: role of coingestants and drugs during intensive care management. Clin Toxicol (Phila). 2010;48(8):845-848.

7. Besecker BY, Exline MC, Hollyfield J, Phillips G, Disilvestro RA, Wewers MD, Knoell DL. A comparison of zinc metabolism, inflammation, and disease severity in critically ill infected and noninfected adults early after intensive care unit admission. Am J Clin Nutr. 2011;93(6): $1356-1364$.

8. Dinsdale D, Williams RB. The enhancement by dietary zinc deficiency of the susceptibility of the rat duodenum to colchicine. Br J Nutr. 1977; 37(1):135-142.

9. Finkelstein Y, Aks SE, Hutson JR, et al. Colchicine poisoning: the dark side of an ancient drug. Clin Toxicol (Phila). 2010;48(5): 407-414.
Drug Design, Development and Therapy

\section{Publish your work in this journal}

Drug Design, Development and Therapy is an international, peerreviewed open-access journal that spans the spectrum of drug design and development through to clinical applications. Clinical outcomes, patient safety, and programs for the development and effective, safe, and sustained use of medicines are the features of the journal, which

\section{Dovepress}

has also been accepted for indexing on PubMed Central. The manuscript management system is completely online and includes a very quick and fair peer-review system, which is all easy to use. Visit http://www.dovepress.com/testimonials.php to read real quotes from published authors. 